\title{
Taste the texture. The relation between subjective tactile sensitivity, mouthfeel and picky eating in young adults
}

Citation for published version (APA):

Nederkoorn, C., Houben, K., \& Havermans, R. C. (2019). Taste the texture. The relation between subjective tactile sensitivity, mouthfeel and picky eating in young adults. Appetite, 136, 58-61. https://doi.org/10.1016/j.appet.2019.01.015

Document status and date:

Published: 01/05/2019

DOI:

10.1016/j.appet.2019.01.015

Document Version:

Publisher's PDF, also known as Version of record

\section{Document license:}

Taverne

Please check the document version of this publication:

- A submitted manuscript is the version of the article upon submission and before peer-review. There can be important differences between the submitted version and the official published version of record.

People interested in the research are advised to contact the author for the final version of the publication, or visit the DOI to the publisher's website.

- The final author version and the galley proof are versions of the publication after peer review.

- The final published version features the final layout of the paper including the volume, issue and page numbers.

Link to publication

\footnotetext{
General rights rights.

- You may freely distribute the URL identifying the publication in the public portal. please follow below link for the End User Agreement:

www.umlib.nl/taverne-license

Take down policy

If you believe that this document breaches copyright please contact us at:

repository@maastrichtuniversity.nl

providing details and we will investigate your claim.
}

Copyright and moral rights for the publications made accessible in the public portal are retained by the authors and/or other copyright owners and it is a condition of accessing publications that users recognise and abide by the legal requirements associated with these

- Users may download and print one copy of any publication from the public portal for the purpose of private study or research.

- You may not further distribute the material or use it for any profit-making activity or commercial gain

If the publication is distributed under the terms of Article $25 \mathrm{fa}$ of the Dutch Copyright Act, indicated by the "Taverne" license above, 


\title{
Taste the texture. The relation between subjective tactile sensitivity, mouthfeel and picky eating in young adults
}

\author{
Chantal Nederkoorn ${ }^{\mathrm{a}, *}$, Katrijn Houben ${ }^{\mathrm{a}}$, Remco C. Havermans ${ }^{\mathrm{a}, \mathrm{b}}$ \\ ${ }^{a}$ Clinical Psychological Science, Maastricht University, the Netherlands \\ ${ }^{\mathrm{b}}$ Laboratory of Behavioural Gastronomy, Centre for Healthy Eating and Food Innovation, Maastricht University Campus Venlo, the Netherlands
}

\section{A B S T R A C T}

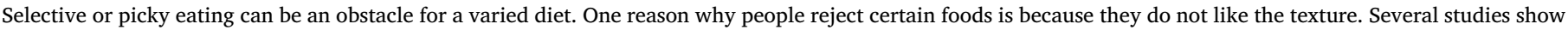

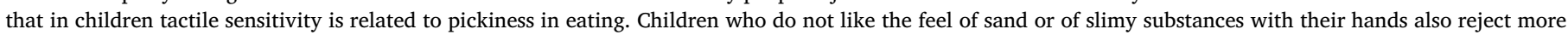

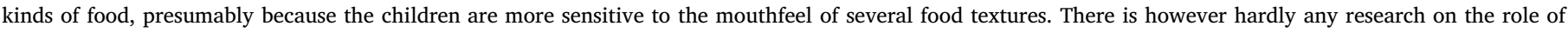

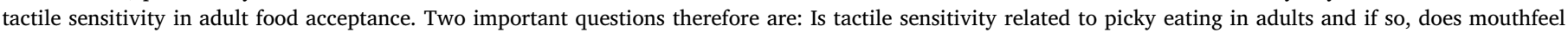

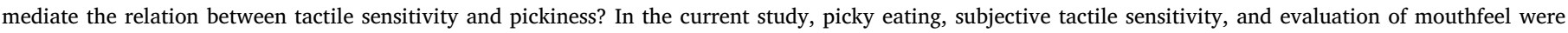

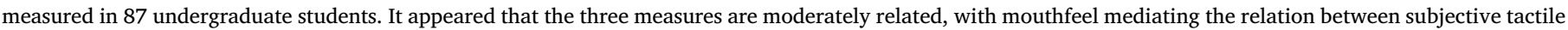

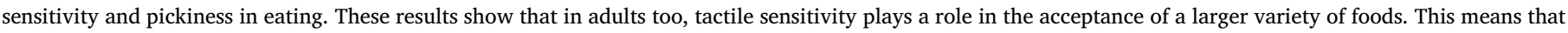
when aiming to change or improve dietary quality of adults, acceptance of food texture should be taken into account.

\section{Introduction}

In order to consume all the essential nutrients, it is important to eat a varied diet (Hodgson, Hsu-Hage, \& Wahlqvist, 1994; Steyn, Nel, Nantel, Kennedy, \& Labadarios, 2006). Eating in a varied way is related to a healthy and prolonged life (Jansen et al., 2004; Kant, Schatzkin, Harris, Ziegler, \& Block, 1993) and one measure of diet quality may be the diversity of the diet (Foote, Murphy, Wilkens, Basiotis, \& Carlson, 2004; Hatloy, Torheim \& Oshaug, 1998). Variety is however diminished if people are very selective or picky about what they like to eat, or if they are unwilling to try unfamiliar foods, also named food neophobic. Indeed, it is found that food neophobia and picky eating is related to poorer quality of diets, in both children and adults (Jarman, Robinson, Lawrence \& Barker, 2017; Knaapila et al., 2015; Volger, Sheng, Toing \& Zhao, 2013).

An important reason why people reject foods is because they do not like them. Besides taste, smell and appearance, texture is a prominent aspect on which liking of food is based (Moskowitz \& Krieger, 1995; Szczesniak, 1991). Texture even plays a decisive role in the aversion to some types of food, like oysters (Scott \& Downey, 2007). In general, food that is tough, gummy, or slimy is disliked more often than food that is crispy or crunchy (Szczesniak, 2002). Children (9-10 years) also dislike bits and pieces in a homogenous texture (De Moura, 2007). One study found that adding pieces to yoghurt made toddlers (32-48 months) dislike it significantly more, while changing the colour of the yoghurt (in green or blue) or the taste (in lemon or apple) did not influence the acceptance of the yoghurt (Werthmann et al., 2015). This shows again the importance of texture in food liking.

Although there are general preferences for specific textures (Szczesniak, 2002), some children appear more sensitive for textures than others. Tactile sensitivity refers to differences in liking or emotional reaction towards textures and the touch of objects, like the feeling of sand, a tooth brush, or specific clothes. These differences are typically explained by differences in detection thresholds, although altered processing of tactile stimulation also appears to play a role (Ide, Yaguchi, Sano, Fukatsu, \& Wada, 2018). Research has showed that children (3-10 years) who are tactile defensive refused more food items (Smith, Roux, Naidoo, \& Venter, 2005). In children with autism and attention deficit hyperactivity disorder (ADHD), this tactile sensitivity is found to be related to oral over-responsivity and in turn to less variety in food selection (Cermak, Curtin, \& Bandini, 2010; Ghanizadeh, 2013). The same relation between tactile sensitivity and selective eating is also found in non-clinical samples of children. Parental report of tactile sensitivity was related to selective eating in children, aged 5-10 (Farrow \& Coulthard, 2012) and to more difficulties in accepting a vegetable in early complementary feeding in a sample of infants (4-6 months) (Coulthard, Harris, \& Fogel, 2016). Moreover, when using behavioural tasks, it was found that children, aged 4-10, who liked more (non-food) textures when feeling them by hand, also appreciated more different types of food (Nederkoorn,

\footnotetext{
* Corresponding author. Maastricht University, Faculty of Psychology and Neuroscience, P.O. Box 616, 6200 MD, Maastricht, the Netherlands.

E-mail address: c.nederkoorn@maastrichtuniversity.nl (C. Nederkoorn).
} 
Jansen, \& Havermans, 2015). In two separate studies, the enjoyment of tactile play in young children ( $2-5$ years) was related to food neophobia (Coulthard \& Sahota, 2016; Coulthard \& Thakker, 2015). The explanation for this relation is that the enjoyment of touching tactile stimuli with hands or skin, is related to enjoyment of food textures in the mouth and this mouthfeel (the way food and drinks feel in the mouth) is in turn related to the acceptance of more foods. Enjoyment of the mouthfeel of different food textures is thus expected to mediate the relation between tactile sensitivity and picky eating.

The relations between tactile sensitivity, food texture, and food acceptance are mainly studied in young children. It is possible that food texture is particularly important for young children, as they have less developed teeth and might be less able to manipulate food in their mouth. Moreover, many foods and textures are new to them. Children might find certain food textures difficult and unpleasant at first, but could adapt to its mouthfeel as they grow older. On the other hand, some children might develop habits of avoiding food with unpleasant textures, which in turn might lead to even higher sensitivity (Dunn, 1997). Overall, studies suggest that for adults, texture of food is still important in the evaluation of food (Moskowitz \& Krieger, 1995; Scott \& Downey, 2007; Szczesniak, 1991). However, the relation between tactile sensitivity and acceptance of food is hardly studied in adults. In one study by Coulthard and Sahota (2016), parents as well as their children were tested and in both groups higher tactile sensitivity was related to more food neophobia. This suggests that in adults tactile sensitivity still plays a role in pickiness in eating and in attaining a varied diet.

In the present study it is tested in adults if enjoyment of tactile stimulation is related to less pickiness in eating. In addition, it is tested if enjoyment of mouthfeel of food mediates this relation. To this aim, undergraduate students evaluated the touch of several objects with different textures by hands as well as the mouthfeel of several foods and they filled out a self-report measure of picky eating.

\section{Method}

\subsection{Participants}

Eighty-nine undergraduate students (age range 18-25 years, 21 males) were recruited from the Faculty of Psychology and Neuroscience, Maastricht University. Two female students reported to have food allergies and were excluded from the taste tests.

\subsection{Measures}

Picky eating was measured by asking participants how much they liked 30 food items, on a 5 point scale, ranging from 1 (not at all/never tried it) to 5 (very much). The list included 30 food items including different preparations (e.g., fresh apples, apple cake, apple sauce; boiled eggs, fried eggs, scrambled eggs; fresh broccoli, cooked broccoli, broccoli soup, French fries, potato soup, mashed potatoes, guacamole, fresh avocado, fresh tomato, mashed tomatoes, fresh mushrooms, fried shrimps, chocolate pudding, chocolate sauce, chocolate bar).

The scores were averaged, with high scores indicating that participants like more types of food and are hence less picky in eating. The Cronbach Alpha value of this measure was .76.

Subjective tactile sensitivity was measured by asking participants to feel nine different objects with different textures, while they were blindfolded (Nederkoorn et al., 2015). The objects were sand, hair jell, marbles, body scrub, sanding paper, hay, wool, velvet and slime (a commercial toy). In between, participants were free to wash their hands in a bowl with warm water and use a tissue. For each texture participants were asked to rate on a 5-point scale how much they liked the feel of it, ranging from 1 (not at all) to 5 (very much). The ratings were averaged, with higher scores reflecting higher affective evaluation of the tactile stimuli. The Cronbach's Alpha value of the measure was 0.50.
Evaluation of mouthfeel was measured by asking how much they liked the texture of nine foods, ranging from 1 (not at all) to 5 (very much). To avoid the influence of the sight of the food, participants were blindfolded. Before blindfolding the participants, they received a list with several food items, including the target foods and the participants were informed they would only taste foods from this list. All participants agreed. Participants wore a nose clip to diminish the influence of flavor. Participants received a spoon with the food on it and if they wanted, they could spit out the food in a cup that was provided to them. The food items varied in the texture and included some more slippery, slimy or spongy textures people typically find difficult: fresh mushrooms, canned mushrooms and mushroom soup (warm), fresh tomatoes, canned tomatoes and tomato soup (warm), fresh peach, peach marmalade and canned peach. The scores were averaged and higher scores indicated that they evaluated the mouthfeel of the foods higher. The Cronbach's Alpha value of this measure was .64.

\subsection{Procedure}

All participants were tested individually. First, they filled out the picky eating questionnaire. Next, they performed the evaluation of touch and finally the evaluation of mouthfeel. The participants were told before the taste test that the foods used during this test were selected from the picky eating questionnaire, but not which foods were selected. They were asked if they were willing to taste this unknown selection blindfolded, and all participants agreed.

\subsection{Statistical analyses}

Univariate linear regressions were performed to test the relations between the three variables. To test for mediation, a hierarchal linear regression was conducted, with picky eating as dependent variable (DV), tactile sensitivity as independent variable (IV) in the first step and mouthfeel as mediator in the second step. Sobel's z was used to test the indirect effect of the IV via the mediator. All variables were centered before entering them in the regression analyses.

\section{Results}

The distribution of the scores on the three variables is depicted in Fig. 1 .

Tactile sensitivity $(\mathrm{M}=3.08, \mathrm{SD}=0.54)$ was a significant predictor of mouthfeel $(\mathrm{M}=2.82, \quad \mathrm{SD}=0.46 ; \quad b=0.354, \quad F(1,85)=8.85$, $p=.001)$ and of picky eating $(\mathrm{M}=3.68, \mathrm{SD}=0.40 ; b=0.304, F$ $(1,85)=8.63, p=.004)$. Mouthfeel was a significant predictor of picky eating $(b=0.338, F(1,85)=10.98, p=.001)$.

\subsection{Mediation analyses}

A hierarchal linear regression was conducted, with picky eating as DV, tactile sensitivity as IV in the first step and mouthfeel as mediator in the second step. Tactile sensitivity was a significant predictor of picky eating, $(b=.304, F(1,85)=8.63, p=.004)$. In block 2 , the mediator (mouthfeel) significantly added to the explained variance $(\Delta$ $\left.r^{2}=0.061, b=0.264, F(1,84)=6.04, p=.016\right)$. When the mediator was entered in block 2 , the coefficient of tactile sensitivity decreased: $b=0.210, p=.054$. This decrease appeared reliable, Sobel's $z=2.02$, $p=.044$ See Fig. 2 . This shows that indeed the evaluation of mouthfeel mediates the relation between tactile sensitivity and picky eating.

\section{Discussion}

The results show that in adults, tactile sensitivity is related to picky eating. As hypothesized, this relation was mediated by the appreciation of mouthfeel. Participants who disliked textures more when feeling them by hand, also disliked the mouthfeel of different foods more and 


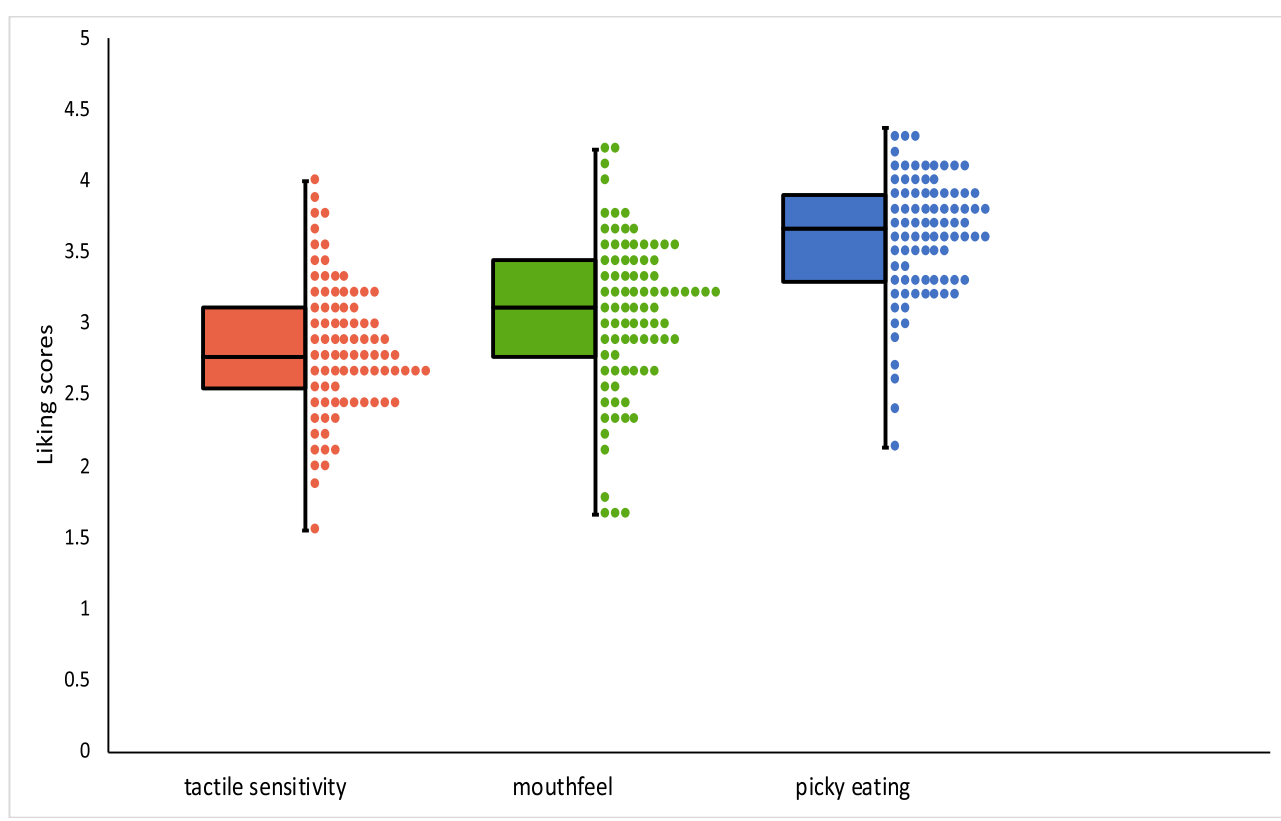

Fig. 1. Boxplot-scatterplot of the scores on subjective tactile sensitivity, mouthfeel and picky eating.

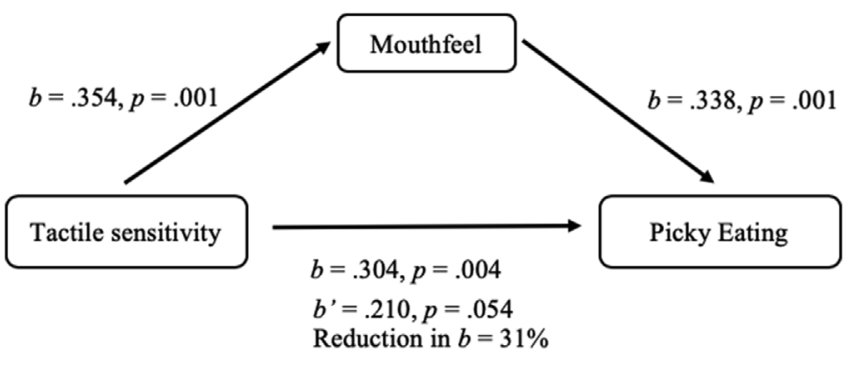

Fig. 2. Results of the mediation analysis of tactile sensitivity, mouthfeel and picky eating.

in turn liked fewer foods. This corroborates previous findings (Coulthard \& Sahota, 2016) and shows that tactile sensitivity not only plays a role in food acceptance in children but also in adults. The effect sizes of the relations between tactile sensitivity, mouthfeel and picky eating are moderate, probably because food liking is determined by many factors including taste, colour, smell, and expectancy. However, the current study shows, again, that texture is nonetheless an important food stimulus attribute and that individual variation in sensitivity to textures can at least partly explain pickiness in eating.

Variety in food intake is important for healthy living, especially when considering fruit and vegetables (Kant et al., 1993; Slavin \& Lloyd, 2012). Can the knowledge from the present study help us in increasing dietary variety? In children, it has been shown that manual exposure to certain textures can increase the liking for food with similar textures (Nederkoorn, Theißen, Tummers, \& Roefs, 2018). Thus, feeling jelly with hands increases liking for jelly desserts. Sensory play with fruit and vegetables, in which children played with foods manually, increases the willingness to taste fruits and vegetables (Coulthard \& Sealy, 2017). In adults, exposure to disliked textures could therefore also increase the liking of those textures. At this moment, possible longterm effects have not been shown however, and it might be a challenge to convince adults to participate in sensory play. Another approach could be to adjust textures of dishes, making them more acceptable. Preparation of foods can influence their crunchiness, sliminess, softness and easiness to handle, and this in turn influences the liking of foods (Zeinstra, Koelen, Kok, \& De Graaf, 2010). This effect could be larger for people who are more tactile sensitive and have less tolerance for specific textures. Specific recipes to make the texture of some fruits and vegetable more acceptable, could therefore increase their intake.

The present sample of adults (i.e. undergraduate students) was still rather young and it might be interesting to study the role of tactile sensitivity in a sample of elderly people. Food intake, both quantity and quality, is often a concern in elderly people (Bernstein et al., 2002; Drewnowski \& Shultz, 2001). It has been suggested that, at least for a subsample, texture becomes more important in the evaluation of foods, to compensate for loss of sensitivity to taste and olfactory stimuli (Forde \& Delahunty, 2004; Kremer, Bult, Mojet, \& Kroeze, 2007). In addition, dental problems can promote the consumption of soft, easily chewed foods (Hays \& Roberts, 2006). It would be interesting to test the role of tactile sensitivity in this group and to examine if tactile exposure or adjustment of food textures could perhaps help in increasing the liking and intake of certain foods.

Similar measures of picky eating and tactile sensitivity were used in a previous study and validity was acceptable (Nederkoorn et al., 2015). The internal consistency of the three measures in the current study was not high, but variation within individuals in liking of diverse foods (or textures) was expected. For establishing the reliability of the measures, future research should therefore focus more on test-retest reliability. Moreover, it would be interesting to test the relation between subjective tactile sensitivity (the liking or emotional responding to various textures) and detection thresholds for touch: do people who dislike more textures have lower thresholds for detection? Are thresholds for detection in fingers and tongue related? And is there a direct relation between thresholds for touch detection and picky eating? In addition, it is possible that some people are more sensitive for other senses as well: they might for instance have stronger subjective responses or lower detection threshold to taste or smell. Indeed, research showed that children who are better able to taste the bitter tastant PROP, sometimes called supertasters, have a reduced liking of bitter tasting vegetables, like broccoli (Keller, Steinmann, Nurse, \& Tepper, 2002). This leads to lower vegetable acceptance in these children (Bell \& Tepper, 2006). Moreover, some studies suggest that supertasters are more sensitive to texture of food or touch in the mouth (Reynolds, Kreider, Meeley, \& Bendixen, 2015; Yackinous \& Guinard, 2001). This would imply crossmodality sensitivity. Future research should therefore look into the interaction of sensitivity of the different senses and how they influence liking of food.

In sum, the present study showed that in young adults, tactile sensitivity is related to the appreciation of mouthfeel, which in turn relates 
to pickiness in eating. The acceptance of textures of fruits and vegetables therefore deserves more consideration when aiming to improve the quality of diets in adults.

\section{References}

Bell, K. I., \& Tepper, B. J. (2006). Short-term vegetable intake by young children classified by 6-n-propylthoiuracil bitter-taste phenotype-. American Journal of Clinical Nutrition, 84(1), 245-251.

Bernstein, M. A., Tucker, K. L., Ryan, N. D., O'Neill, E. F., Clements, K. M., Nelson, M. E., et al. (2002). Higher dietary variety is associated with better nutritional status in frail elderly people. Journal of the American Dietetic Association, 102(8), 1096-1104.

Cermak, S. A., Curtin, C., \& Bandini, L. G. (2010). Food selectivity and sensory sensitivity in children with autism spectrum disorders. Journal of the American Dietetic Association, 110, 238-246.

Coulthard, H., Harris, G., \& Fogel, A. (2016). Association between tactile over-responsivity and vegetable consumption early in the introduction of solid foods and its variation with age. Maternal \& Child Nutrition, 12, 848-859.

Coulthard, H., \& Sahota, S. (2016). Food neophobia and enjoyment of tactile play: Associations between preschool children and their parents. Appetite, 97, 155-159.

Coulthard, H., \& Sealy, A. (2017). Play with your food! Sensory play is associated with tasting of fruits and vegetables in preschool children. Appetite, 113, 84-90.

Coulthard, H., \& Thakker, D. (2015). Enjoyment of tactile play is associated with lower food neophobia in preschool children. Journal of the Academy of Nutrition and Dietetics, 115, 1134-1140.

Drewnowski, A., \& Shultz, J. M. (2001). Impact of aging on eating behaviors, food choices, nutrition, and health status. The Journal of Nutrition, Health \& Aging, 5, 75-79.

Dunn, W. (1997). The impact of sensory processing abilities on the daily lives of young children and their families: A conceptual model. Infants \& Young Children, 9, 23-35.

Farrow, C. V., \& Coulthard, H. (2012). Relationships between sensory sensitivity, anxiety and selective eating in children. Appetite, 58, 842-846.

Foote, J. A., Murphy, S. P., Wilkens, L. R., Basiotis, P. P., \& Carlson, A. (2004). Dietary variety increases the probability of nutrient adequacy among adults. Journal of Nutrition, 134, 1779-1785.

Forde, C. G., \& Delahunty, C. M. (2004). Understanding the role cross-modal sensory interactions play in food acceptability in younger and older consumers. Food Quality and Preference, 15, 715-727.

Ghanizadeh, A. (2013). Parents reported oral sensory sensitivity processing and food preference in ADHD. Journal of Psychiatric and Mental Health Nursing, 20, 426-432.

Hatløy, A., Torheim, L. E., \& Oshaug, A. (1998). Food variety—a good indicator of nutritional adequacy of the diet? A case study from an urban area in Mali, west Africa. European Journal of Clinical Nutrition, 52, 891.

Hays, N. P., \& Roberts, S. B. (2006). The anorexia of aging in humans. Physiology \& Behavior, 88, 257-266.

Hodgson, J. M., Hsu-Hage, B. H. H., \& Wahlqvist, M. L. (1994). Food variety as a quantitative descriptor of food intake. Ecology of Food and Nutrition, 32, 137-148.

Ide, M., Yaguchi, A., Sano, M., Fukatsu, R., \& Wada, M. (2018). Higher tactile temporal resolution as a basis of hypersensitivity in individuals with autism spectrum disorder. Journal of Autism and Developmental Disorders, 1-10.

Jansen, M. C., Bueno-de-Mesquita, H. B., Feskens, E. J., Streppel, M. T., Kok, F. J., \&
Kromhout, D. (2004). Quantity and variety of fruit and vegetable consumption and cancer risk. Nutrition and Cancer, 48, 142-148.

Jarman, M., Robinson, S. M., Lawrence, W. T., Barker, M. E., Godfrey, K. M., Cooper, C., et al. (2017). OP44 Feeding difficulties and maternal concerns at age 3 years are associated with a decline in children's diet quality to age 6 .

Kant, A. K., Schatzkin, A., Harris, T. B., Ziegler, R. G., \& Block, G. (1993). Dietary diversity and subsequent mortality in the first national health and nutrition examination survey epidemiologic follow-up study. American Journal of Clinical Nutrition, 57 434-440.

Keller, K. L., Steinmann, L., Nurse, R. J., \& Tepper, B. J. (2002). Genetic taste sensitivity to 6-n-propylthiouracil influences food preference and reported intake in preschool children. Appetite, 38, 3-12.

Knaapila, A. J., Sandell, M. A., Vaarno, J., Hoppu, U., Puolimatka, T., Kaljonen, A., et al. (2015). Food neophobia associates with lower dietary quality and higher BMI in Finnish adults. Public Health Nutrition, 18, 2161-2171.

Kremer, S., Bult, J. H., Mojet, J., \& Kroeze, J. H. (2007). Food perception with age and its relationship to pleasantness. Chemical Senses, 32, 591-602.

Moskowitz, H. R., \& Krieger, B. (1995). The contribution of sensory liking to overall liking: An analysis of six food categories. Food Quality and Preference, 6, 83-90.

Nederkoorn, C., Jansen, A., \& Havermans, R. C. (2015). Feel your food. The influence of tactile sensitivity on picky eating in children. Appetite, 84, 7-10.

Nederkoorn, C., Theißen, J., Tummers, M., \& Roefs, A. (2018). Taste the feeling or feel the tasting: Tactile exposure to food texture promotes food acceptance. Appetite, 120, 297-301.

Reynolds, S., Kreider, C. M., Meeley, L. E., \& Bendixen, R. M. (2015). Taste perception and sensory sensitivity: Relationship to feeding problems in boys with Barth Syndrome. The Journal of rare disorders, 3, 1-9.

Scott, C. L., \& Downey, R. G. (2007). Types of food aversions: Animal, vegetable, and texture. Journal of Psychology, 141, 127-134.

Slavin, J. L., \& Lloyd, B. (2012). Health benefits of fruits and vegetables. Advances in nutrition, 3, 506-516.

Smith, A. M., Roux, S., Naidoo, N. R., \& Venter, D. J. (2005). Food choices of tactile defensive children. Nutrition, 21, 14-19.

Steyn, N. P., Nel, J. H., Nantel, G., Kennedy, G., \& Labadarios, D. (2006). Food variety and dietary diversity scores in children: Are they good indicators of dietary adequacy? Public Health Nutrition, 9, 644-650.

Szczesniak, A. S. (1991). Textural perceptions and food quality 1. Journal of Food Quality, $14,75-85$.

Szczesniak, A. S. (2002). Texture is a sensory property. Food Quality and Preference, 13, 215-225.

Volger, S., Sheng, X., Tong, M., Zhao, D., Leung, T., \& Zhang, F. (2013). Dietary patterns and nutrients intakes of preschool children with picky-eating behaviours. ESPGAN, $201313 \mathrm{e} 1141$.

Werthmann, J., Jansen, A., Havermans, R., Nederkoorn, C., Kremers, S., \& Roefs, A. (2015). Bits and pieces. Food texture influences food acceptance in young children. Appetite, 84, 181-187.

Yackinous, C., \& Guinard, J. X. (2001). Relation between PROP taster status and fat perception, touch, and olfaction. Physiology \& Behavior, 72, 427-437.

Zeinstra, G. G., Koelen, M. A., Kok, F. J., \& De Graaf, C. (2010). The influence of preparation method on children's liking for vegetables. Food Quality and Preference, 21 906-914. 